Forthcoming in the Journal for the Scientific Study of Religion

https://doi.org/10.1111/jssr.12521

\title{
Religion and Disability: Variation in Religious Service Attendance Rates for Children with Chronic Health Conditions
}

ANDREW L. WHITEHEAD

Department of Sociology, Anthropology, \& Criminal Justice

Clemson University

Prior research consistently demonstrates greater religious involvement is associated with improved health outcomes for those with chronic health conditions. Fewer studies focus on how chronic health conditions influence religious service attendance rates and most focus on older Americans. Using three waves of a nationally representative sample of children in the United States, I test whether children with a chronic health condition never attend religious worship services at rates significantly higher than children without a condition. I also investigate variation in attendance rates across a broad range of conditions, something previously overlooked.

Children with chronic health conditions are more likely to never attend religious worship services. Specifically, children with chronic health conditions that impede communication and social interaction are most likely to never attend. Despite shifts in prevalence these findings are stable over time. Implications for researchers, religious communities, families with children with chronic health conditions, and healthcare providers are discussed.

Keywords: Chronic health condition, Disability, Health, Children, Religion, Congregations, United States

Acknowledgements: The author would like to thank the editor of JSSR, three anonymous reviewers, Ye Luo, and Joseph Baker for their insightful comments on previous drafts. Any error(s) or omissions remain the author's alone. Special thanks to Kelly, Joel, Natalie, and Theo Whitehead for their enduring inspiration and commitment to flourish regardless of disability.

Please direct all correspondence to Andrew L. Whitehead, 132 Brackett Hall, Clemson University, Clemson, SC 29634.Email: alw6@clemson.edu. 


\section{INTRODUCTION}

\section{Religious Service Attendance and Chronic Health Conditions}

Up to twenty percent of Americans report a chronic health condition or disability of some kind (CDC 2015; Erickson, Lee, von Schrader 2017). ${ }^{1}$ These chronic health conditions include motor difficulties, visual or hearing complications, self-care limitations, or cognitive impairments. While the passage of the Americans with Disabilities Act (ADA) in 1990 improved the lives and welfare of Americans living with chronic health conditions in a few areas, significant progress remains elusive. Americans with chronic health conditions continue to face higher levels of poverty, much lower employment rates, lower annual income, lower life satisfaction, reduced access to necessary healthcare, and lower educational attainment than Americans with no reported chronic health conditions (Erickson et al. 2017; Kessler 2010). Participation in various aspects of social life, like going to restaurants or socializing with friends, neighbors, or relatives is rarer for those with chronic health conditions. Chronic health conditions also significantly influence Americans' participation in religious activities such as attendance at worship services.

Individuals with disabilities consider faith to be important to them at rates similar to the population with no reported disabilities (Carter 2007). Despite this, 50 percent of people with a chronic health condition report attending religious services at least once per month, while 57 percent of people without a chronic health condition report the same - a seven percent gap.

\footnotetext{
${ }^{1}$ Throughout the manuscript I use the term "chronic health condition" as it is more inclusive of a broad range of health problems than is the term "disability" (Bernell and Howard 2016). As Bernell and Howard (2016) state, chronic health condition refers to conditions, disabilities, or diseases that have a long development and duration, have a complex causality, have a prolonged course of illness, and may include associated functional impairment or disability. My use of chronic health condition also follows the terminology adopted by the agencies collecting the data used in these analyses (Centers for Disease Control and Prevention, National Center for Health Statistics, U.S. Department of Health and Human Services, Health Resources and Services Administration, Maternal and Child Health Bureau).
} 
Thirty-five percent of people with a chronic health condition report never attending religious services while only 26 percent of people without a disability report the same - a nine percent gap (Kessler 2010). Several studies find that among older Americans attendance at religious services wanes as chronic health conditions, disability, and functional limitations increase (Barusch 1999; Gillum and Trulear 2008). Another study demonstrates that disability due to various physical injuries is significantly associated with less frequent attendance at religious services (Campbell, Yoon, and Johnstone 2010). Demonstrating variation in attendance at religious services for those with chronic health conditions is important given attendance has a stable association with longterm health trajectories (Koenig, King, and Carson 2012) and is linked to a number of beneficial outcomes such as lower rates of mortality, slowing functional decline, reducing depression, and improving mental health (Ellison and Levin 1998; Hayward and Krause 2013; Hill et al. 2005; Hummer et al. 2010; Idler and Kasl 1997a, 1997b; Koenig et al. 1997; Koenig et al. 1999; Levin and Chatters 1998; Vogel, Polloway, and Smith 2006).

One limitation of the aforementioned studies regarding chronic health conditions and religious service attendance is that a majority focus on adults and especially older Americans. This is unfortunate given about one in six children report at least one developmental disability, a 17 percent increase in prevalence from 1997 to 2008 (Boyle et al. 2011). Furthermore, a handful of studies of children with chronic health conditions highlight the beneficial effects of religious service attendance. Consistent attendance at religious services among children and adolescents with various chronic health conditions is generally associated with improved mental and emotional health, higher self-esteem, and overall well-being (Abbotts et al. 2004; Ault 2010; Kleinert et al. 2007; Meltzer et al. 2011; Swinton 2001). Prior research also demonstrates a range of positive outcomes for family members of children with chronic health conditions who attend 
religious services: increased social support, improved physical health, and better mental/emotional health (Bayat 2007; Bennett et al. 1995; Coulthard and Fitzgerald 1999; O’Hanlon 2013; Phelps et al. 2009; Poston and Turnbull 2004; Tarakeshwar and Pargament 2001; White 2009; Whitehead 2016; Yatchmenoff et al. 1998).

To date there are no large-scale, multiple time point, quantitative analyses of the association between chronic health conditions and children's religious service attendance in the United States. The current analysis aims to fill this void. Using three waves of nationally representative samples of children in the United States, this study tests two hypotheses concerning the association between reported chronic health conditions and children's religious service attendance across multiple years. A number of implications for children with chronic health conditions, their families, as well as organized religion emerge from these findings. Multiple avenues for future research are also apparent in the understudied area of health and religion among children.

\section{Explaining Variation in Religious Service Attendance Rates among Children with Chronic Health Conditions}

There are a number of possible explanations why children with chronic health conditions struggle to attend worship services at rates similar to those without chronic health conditions. Generally, most religious congregations have been slow to respond to the needs of families with chronically disabled children. The 2001 U.S. Congregational Life Survey found that only ten percent of congregations report offering some form of care for people with disabilities (Woolever and Bruce 2002). Carter (2007) identified several aspects of congregations that can create barriers to inclusion for those with chronic health conditions and their families. These congregational hurdles include architectural, attitudinal, communication, programmatic, and 


\section{CHILDHOOD DISABILITY AND RELIGION}

liturgical barriers. Ault, Collins, and Carter (2013b) demonstrate that due to these and other barriers, 33 percent of parents of children with chronic health conditions changed their place of worship because they felt their child was not included. Fifty-six percent reported keeping their child from participating in religious activities due to lack of support, and about half stated that they had never been asked by their congregation how to best include their child. More than half of these parents recount having been expected to stay with their child throughout worship services in order for their child to participate (Ault, Collins, Carter 2013a). Congregational barriers limit parents' ability to participate and integrate into a worship community.

Due to various congregational barriers, negative mental and emotional outcomes are commonly associated with religious activity among parents - like attending religious worship services - while more positive mental and emotional outcomes are associated with religious belief and spirituality (Ekas et al. 2009; Poston and Turnbull 2004; Shu 2009; Tarakeshwar and Pargament 2001). Parents of children with chronic health conditions consistently share how attendance at religious services creates opportunities for negative interactions and general unresponsiveness from congregations and their members. Many parents of children with chronic health conditions suffer from fatigue due to advocating for their child in various other spheres of social life. The effort required to attend religious services is viewed as too much additional labor. As one mother shares, "We wish we had a community to belong to, however . . . we have not had the time or energy to seek-out and prepare (educate) a new spiritual home for ourselves" (Ault et al. 2013b: 200). Attending religious services can have divergent effects from offering much needed social and emotional support to being a cause of additional stress and distress for children with chronic health conditions and their families (Tarakeshwar and Pargament 2001). A few prior studies focus on children with chronic health conditions and demonstrate variation in their 
religious service attendance rates compared to children without a chronic health condition. For instance, among adults and adolescents with autism spectrum disorders, 44 percent attend religious services less than yearly (Orsmond, Krauss, and Seltzer 2004). ${ }^{2}$ Less than one-third attend at least once per week. Two studies of adolescents and children in Great Britain found that those with conduct disorders and depression were less likely to attend religious services regularly (Abbotts et al. 2004; Meltzer et al. 2011). Congregational barriers and their effects on parents and families of children with chronic health conditions may be one reason why these children attend religious services less often than their peers leading to the first hypothesis of this study:

H1: Compared to children with no reported health conditions, children with any reported chronic health condition will be more likely to never attend religious worship services. In addition to the clear organizational barriers that exist within congregations, the behavioral features of each child with a chronic health condition can significantly influence their integration into congregational life and their frequency of worship service attendance (Ault et al. 2013b). This suggests that differences in religious service attendance might exist across a range of childhood chronic health conditions. For example, a child with a chronic health condition where the limitations tend to be more physical in nature - like asthma or diabetes - may be able to attend religious services more easily than a child with a chronic health condition that limits their capacity to communicate and interact socially, such as a child who is non-verbal and on the autism spectrum. Of the few studies discussed above that examine religious service attendance rates for various childhood chronic health conditions, even fewer focus on more than one and even then the investigation is limited to only a small number of chronic health conditions. While prior work in this area suggests that there are indeed differences in attendance rates across

\footnotetext{
${ }^{2}$ By way of comparison, in 200422.7 percent of American adults report attending "less than once per year" or "never" (General Social Survey, 2004).
} 
various childhood chronic health conditions, to date there are no studies that examine a broad range of childhood chronic health conditions and their association with attendance at worship services.

Using data collected in 2003, Lee and colleagues (2008) find that children and adolescents with autism spectrum disorders are less likely to attend religious services at least once per week compared to those with ADD/ADHD or no intellectual disability. They also find in bivariate analyses that significantly fewer children and adolescents with ADD/ADHD attend religious services on a regular basis compared to children and adolescents with no disability. Wagner and colleagues (2003) find some variation across chronic health condition categories regarding participation in religious services. The proportion of children and adolescents with a chronic health condition who participated in religious activities in the last year range from a low of 44 percent for those with deaf-blindness to a high of 54 percent for those with an orthopedic impairment. Because different chronic health conditions present a range of possible difficulties, there is likely variation across chronic health conditions in the probability of never attending religious services leading to a second hypothesis:

H2: The likelihood of never attending religious services will vary depending on children's particular chronic health condition.

Finally, it is important to document the association between children's religious service attendance and chronic health conditions across time because of shifts in the prevalence of some conditions. From 2002 to 2008, there was a 78 percent increase in prevalence of autism spectrum disorders where an estimated 1 in 88 children were identified with an autism spectrum disorder in 2008, which then increased to 1 in 68 children by 2010 (Baio 2014). The prevalence of everdiagnosed ADHD increased 42 percent from 2003 to 2011 (Visser et al. 2014). Other 
developmental delays, broadly defined, also increased from the late 1990s until 2008 (Boyle et al. 2011). Hearing loss, however, shows signs of decreasing prevalence over the same time period (Boyle et al. 2011). The following analyses tests these hypotheses using three waves of data to determine if the association between particular chronic health conditions and never attending religious services is consistent over time.

\section{DATA AND METHODS}

This analysis draws on data from three waves of the National Survey of Children's Health (2003, 2007, 2011-2012) conducted by the Centers for Disease Control and Prevention (CDC), National Center for Health Statistics. This survey is sponsored by the U.S. Department of Health and Human Services, Health Resources and Services Administration, and Maternal and Child Health Bureau (2005, 2009, 2012). The NSCH gathered a broad range of information including demographics, health insurance coverage, health and functional status, health care access, parental health status, family functioning, and community characteristics.

The 2003, 2007, and 2011-2012 NSCH are each nationally representative samples of non-institutionalized children and youth aged 0-17 living in all 50 states and the District of Columbia. Each wave uses a complex survey design stratified by state, and in the case of the 2011-2012 wave, sample type as well. The NSCH uses random-digit dialing techniques to contact households to then screen for presence of a child in the home. The interviews are completed by parents/caregivers of children. In the 2011-2012 wave 95,677 phone interviews, using both landline and cell phone numbers, were completed by parents/caregivers. Completed interviews per state ranged from 1,811 to 2,200 . The cell phone sample was new for the 20112012 wave of the survey and the completion rate - proportion of households known to include 


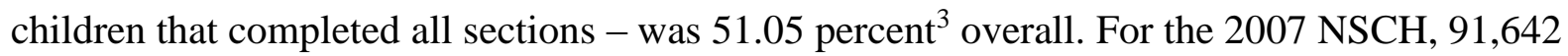
interviews were completed, between 1,725 and 1,932 per state. The overall completion rate was 66.0 percent. A total of 102,353 surveys were completed in the 2003 wave, between 1,483 and 2,241 per state. The completion rate was 68.8 percent. Please see Blumberg et al. (2005), Blumberg et al. (2012), and Blumberg et al. (2013) for additional information about each wave of the NSCH. All three waves of the NSCH public use data files and additional documentation are available through www.childhealthdata.org.

When possible, the following analyses draw on each of the three available waves to determine if there are changes regarding which chronic health conditions are significantly associated with never attending religious services across the intervening decade. It also allows for tests of whether the association between particular chronic health conditions and never attending religious services is different depending on survey year.

\section{Measures}

Dependent Variable. Each wave of the NSCH asks, "About how often does [child name] attend religious service?” In all three waves the possible response categories were, "None”, "At least once per year, but less than once per month", "At least once per month, but less than once per week", "At least once per week", and "More than once per week". This measure was dichotomized such that $1=$ never attends a religious service. In 2003, 21.4 percent of children in the US never attended a religious service. In 2007, 20.7 percent reported the same about their child's religious service attendance. In 2011-2012, 23.5 percent of children never attended a religious service (see Table 1). Focusing on never attending religious services provides the most clarity regarding the influence of the various chronic health conditions. The overly general nature

\footnotetext{
${ }^{3} 54.1$ percent for the landline sample $(\mathrm{N}=63,705)$ and 41.2 percent for the cell-phone sample $(\mathrm{N}=31,972)$.
} 
of the other response categories limits clear interpretation of exactly how often these children are attending.

[Table 1 about here]

Chronic Health Conditions. In all three waves of the NSCH respondents were read a list of conditions and asked: "Has a doctor or other health care provider ever told you that [child's name] had [particular chronic health condition].” In 2003 there were 10 possible chronic conditions. This list expanded to 16 in 2007 with two additional chronic conditions added in 2011-2012 to bring the total to 18 . There are eight chronic conditions that were consistently measured across all three waves. The conditions and the waves on which they appear include autism spectrum disorder (2003, 2007, 2011-2012), attention deficit disorder (2003, 2007, 20112012), developmental delay (2003, 2007, 2011-2012), learning disability (2003, 2007, 20112012), oppositional defiant disorder/conduct disorder (2003, 2007, 2011-2012), asthma (2003, 2007, 2011-2012), diabetes (2003, 2007, 2011-2012), bone/joint/muscle problems (2003, 2007, 2011-2012), depression (2007, 2011-2012), anxiety (2007, 2011-2012), speech problems (2007, 2011-2012), Tourette Syndrome (2007, 2011-2012), brain injury/concussion (2007, 2011-2012), epilepsy (2007, 2011-2012), hearing problems (2007, 2011-2012), vision problems (2007, 20112012), intellectual disability (2011-2012), cerebral palsy (2011-2012), hearing or vision problems (2003), and depression or anxiety (2003). ${ }^{4}$ The NSCH also designates age ranges for certain conditions to account for the fact that some chronic health conditions may not manifest in full until a later age. For instance, while vision problems may clearly manifest before age 2, intellectual or conduct disorders can be much more difficult to diagnose until after age 2 .

\footnotetext{
${ }^{4}$ In 2003, the NSCH combined depression and anxiety into one question. These were later separated in the 2007 and 2011-2012 surveys. The 2003 version also combined hearing and vision problems into one question. The 2007 and 2011-2012 surveys asked these separately as well.
} 
In order to compare each chronic health condition to children with no reported conditions in the multivariate models, I created three groups for each health condition: Those with the condition (Condition Present), those with any other reported chronic health condition but not the condition in question (Condition Absent - Other Condition(s) Present), and those with no reported chronic health conditions (No Condition(s) Present). In all of the multivariate models, the No Condition(s) Present group is used as the contrast category. This allows us to assess if each reported health condition significantly raises children's probability of never attending religious services compared to children with no reported health conditions. Creating the Condition Absent - Other Condition(s) Present category helps maintain the clarity of the Condition Present and No Condition(s) Present groups. It also allows us to preserve cases. While the results from this group are presented below I refrain from drawing any substantive conclusions given that it is a conceptual catch-all category.

Table 2 displays each of these chronic conditions and their prevalence rates across all three waves with significance tests. It also includes children with no reported chronic health conditions. The most common chronic health condition within each of these three waves is asthma with 8.6 percent of children affected in 2011-2012. Attention deficit disorder/attention deficit hyperactivity disorder (ADD/ADHD) is the second most common condition in 2011-2012 wave - 7.9 percent of children affected, but third-most in the 2007 and 2003 waves. Learning disability is the third most common in 2011-2012 - 7.8 percent of children affected - but second most common on the 2007 and 2003 waves.

[Table 2 about here]

Control Variables. In addition to chronic health conditions influencing children's religious service attendance, a variety of social and demographic indicators are included as control 
variables in the following analyses. ${ }^{5}$ Age (in years, $\left.0-17\right)$, child's health $(5=$ excellent to $1=$ poor), race/ethnicity (white, Hispanic, black, multiple or other race), gender $(1=$ female), family structure (two biological/adoptive parents, two parent stepfamily, single mother, other family type), parents' income $(1=<100 \%$ FPL to $4=400 \%$ or more FPL), parents' education (highest level attained by any parent, 1 = less than HS, 2 = HS graduate, $3=$ More than HS), size of place $(1=$ Urban), region (Northeast, Midwest, South, West), and survey year (where applicable) are all included as controls (see Table 1).

\section{Methods}

Each wave of the NSCH uses a complex sampling design. For the 2003 and 2007 waves, the survey is designed to provide independent data sets for each state. In the 2011-2012 wave, the complex design accounts for state and for sample type. A specific program within SAS V 9.3 (PROC SURVEY) has the capacity to account for complex sampling design and was used throughout this analysis in order to properly calculate variances, standard errors, and confidence intervals. Every record in each wave of the NSCH is assigned a single sampling weight. These weights are used throughout the analysis in order to provide accurate point estimates. This analysis uses binary logistic multivariate modeling, due to the coding of the dependent variable, while simultaneously employing the necessary complex sampling design procedures. ${ }^{6}$

Table 3 displays the results for 21 separate binary logistic regression models for all of the chronic health conditions for which data was collected in the 2011-2012, 2007, and 2003 waves

\footnotetext{
5 The severity of certain chronic health conditions can moderate the influence these conditions have on a child's life. In the 2011-2012 and $2007 \mathrm{NSCH}$, parents/guardians were asked to rate the severity of a handful of chronic health conditions. In 2003, respondents were not asked about the severity of any chronic health condition. Due to this lack of consistent measurement of severity, the following analyses cannot control for it in a comprehensive manner.

${ }^{6}$ Ancillary analyses examined OLS regression models and a dependent variable (attend) that ranged from 0 (Never attend) to 3 (Attend once per week or more) and the results did not differ from those presented below. All chronic health conditions exhibited significant effects in an identical direction with the exception of brain injury which was non-significant.
} 
of the NSCH. ${ }^{7}$ Controlling for survey year (where applicable), the analyses depicted in Table 3 allow us to determine if the association between the various chronic health conditions and never attending religious services is consistent across time. In ancillary analyses (not shown but available upon request) interaction terms for survey year and each chronic health condition were estimated to determine if any effects were moderated by survey year (see footnote 9 for more information). In each table, each row displays the coefficients for the Condition Present and the Condition Absent - Other Condition(s) Present categories which are being compared to the No Condition(s) Present group which serves as the contrast category. Again, I refrain from drawing any substantive conclusions regarding the coefficients for the Condition Absent - Other Condition(s) Present category since it is a conceptual catch-all category. In the interest of space the coefficients for the various control variables are not displayed in the table. Full results are available upon request. Please see footnote 8 for general information about the number of models in which particular control variables were non-significant.

\section{RESULTS}

Table 2 provides the percent of children affected by each chronic health condition - with notations to designate if the prevalence rate in 2011-2012 is significantly higher than in 2007 or 2003 - and the percent within each of these groups that never attend religious services.

Additional notations designate if the percent of children with each chronic health condition who

\footnotetext{
${ }^{7}$ I also examined the full collection of chronic health conditions for each wave separately (see online supplementary tables). The findings from the merged models (Table 3) are identical to those models across separate survey waves except in four instances where there is slight variation. ADD/ADHD is significant in the merged models (as it is in 2007 and 2003) while in 2011-2012 it is non-significant. Hearing problems is non-significant in the merged models (as it is in 2007) while in 2011-2012 it is significant (it was not asked in 2003). Bone/joint/muscle problems is significant in the merged models (as it is in 2003) while in 2011-2012 and 2007 it is non-significant. Brain injury is significant in the merged models (as it is in 2011-2012) while in 2007 it is non-significant (it was not asked in 2003). There are no instances where a chronic health condition exhibits a significant association in one direction in the merged models but is significantly associated in the opposite direction in any of the separate survey wave models.
} 
never attend is significantly different than the percent of children with no health condition who never attend. Within each wave of the $\mathrm{NSCH}$, children with autism spectrum disorders have the highest reported frequency of never attending religious services. Furthermore, the percent of children with autism spectrum disorders who never attend is consistently significantly higher than children with no chronic health conditions. In 2011-2012, 32.1 percent of children with an autism spectrum disorder report never attending religious services. In the same survey year, 24.4 percent of children without a chronic health condition report never attending.

Other chronic health conditions asked across all three waves where significantly more children with that particular chronic health condition report never attending religious services include (with the 2011-2012 percent who never attend in parentheses): ADD/ADHD (23.6), developmental delay (29.3), learning disability (27.1), and oppositional defiant disorder (29.2). Significantly more children with depression (29.9), anxiety (27.7) and speech problems (29.8) never attend in both the 2007 and 2011-2012 surveys when compared to children with no reported conditions.

Several chronic health conditions show a less consistent relationship with never attending religious services. In 2011-2012, significantly more children with hearing problems (26.0) or a brain injury (31.0) report never attending religious services while there are no significant differences between those with these conditions and children with no health conditions in 2007.

While these findings give clear evidence that various chronic health conditions are significantly related to children's never attending religious services, multivariate models are necessary to ensure the relationship is robust. Table 3 displays the results of 21 separate logistic regression models (20 chronic health condition models and one model for children with no reported health conditions) using all three waves the NSCH data (where applicable). Each row 
displays the coefficients for each chronic health condition from separate models, and the second through fourth columns contain the coefficients and odds ratios for the Condition Present and Condition Absent - Other Condition(s) Present categories which are being compared to the contrast category, No Condition(s) Present. Each model contains all of the control variables discussed in the data section. The final column provides the sample size for each model along with a notation designating the particular waves of the NSCH included in the analyses. The online supplementary models display the results from each individual survey wave.

Net of all other effects, children with no reported health conditions are significantly less likely $(b=-.127)$ to report never attending religious services across all three waves, even when controlling for survey year. Conversely, the odds of never attending religious services are 1.84 times higher for a child with an autism spectrum disorder compared to children with no conditions. Likewise, for those chronic health conditions present on all three waves, the odds of never attending religious services are higher for children with ADD/ADHD (1.19), developmental delays (1.36), learning disabilities (1.36), oppositional defiant disorder (1.48), and bone/joint/muscle problems (1.15). However, across all three waves, children with asthma and diabetes are not significantly more likely to never attend compared to children with no chronic health conditions.

Several chronic health conditions present on both the 2011-2012 and 2007 waves of the NSCH also show consistent effects. Children with depression (1.73), anxiety (1.45), speech problems (1.42), and brain injury (1.71) all report higher odds of never attending religious services than those children with no reported health conditions. Conversely, children who report having Tourette Syndrome, epilepsy, hearing problems, or vision problems are no more or less likely to never attend compared to children with no reported health conditions. Finally, on the 
2011-2012 wave children with intellectual disability and Cerebral Palsy are not significantly more likely to never attend than children with no health conditions. In the 2003 wave, respondents were simultaneously asked if their child had "hearing or vision problems", or "depression or anxiety". Similar to when depression and anxiety were asked separately on both the 2007 and 2011-2012 waves, children who reported having depression or anxiety in 2003 were significantly more likely to never attend religious services. The findings for hearing or vision problems when asked simultaneously in 2003 mirror those for hearing problems and vision problems when they were asked separately in the 2007 and 2011-2012 waves: no significant differences. ${ }^{8}$

[Table 3 about here]

\section{DISCUSSION AND CONCLUSION}

Across three waves of a nationally representative survey of children in the United States, it is clear that a number of chronic health conditions are significantly associated with never attending religious worship services. In support of the first hypothesis, children with chronic health conditions are more likely to never attend religious services compared to children with no reported health conditions. Furthermore, consistently since 2003, children with autism spectrum disorders, ADD/ADHD, developmental delays, learning disabilities, oppositional defiant disorder/conduct disorders, and bone/joint/muscle problems are all more likely to never attend religious services. Since first asked in 2007, children with speech problems, depression, anxiety, or brain injuries are significantly more likely to never attend religious services compared to children with no reported conditions. Children with asthma, diabetes, Tourette Syndrome,

\footnotetext{
${ }^{8}$ Across all models, all of the control variables were consistently significantly associated with never attending except parents' income (non-significant in 17 models), Midwest (non-significant in four models), and child's health (non-significant in all models). Full model results available upon request.
} 
epilepsy, hearing problems, vision problems, intellectual disabilities, or Cerebral Palsy are no more or less likely to never attend religious services compared to children with no reported chronic health conditions. This variation across various disabilities and chronic health conditions supports the second hypothesis.

Taken together, these analyses unveil a number of important findings. It appears that across a range of chronic health conditions, those that are primarily characterized by deficiencies in social interaction or might impede communication are most consistently and significantly associated with disengagement with attendance at religious worship services. Furthermore, these results strongly suggest that the higher probability of children with particular health conditions never attending religious services has been stable over time. ${ }^{9}$ Prior research signals that this is likely due to factors attributable to barriers within congregations as well as the characteristics of the children's disability. As Ault and colleagues (2013b) point out, the behavioral characteristics of children with various chronic health conditions play an important role in structuring if and how they will be integrated into congregational life. Children with autism spectrum disorders, developmental delays, and conduct disorders all manifest a range of social and behavioral characteristics that routinely result in strained social encounters and interactions. Likewise, children with speech problems might not be able to communicate as easily as their peers. The particular behavioral characteristics or physical limitations associated with these health conditions appear to limit these children's ability to attend religious services.

\footnotetext{
${ }^{9}$ In ancillary models I estimated interactions between each chronic health condition and survey year. Out of the 16 possible interactions between each chronic health condition and survey year in Table 3 only two were significant: $\mathrm{ADD} / \mathrm{ADHD}$ and hearing problems. The majority of non-significant interaction terms suggests that the associations between each chronic health condition and never attending religious services are consistent across survey years with few substantial differences across time. Results available upon request.
} 
Carter's (2007) five congregational barriers - architectural, attitudinal, communication, programmatic, and liturgical - may also be influential in limiting the integration of children with communication and social interaction deficiencies due to various chronic health conditions. Attitudinal, communication, and programmatic barriers might be particularly important regarding never attending religious services. Attitudinal barriers many times include patronizing, disparaging, or paternalistic comments or behaviors, such as questioning whether those with particular chronic health conditions "really get anything out of participating" (Carter 2007:12). Communication barriers include failing to present doctrines and information in new ways so that those who learn using different techniques are not excluded. Programmatic barriers refer to the additional supports that are sometimes necessary for those with chronic health conditions to participate. Many children with developmental disabilities, like those who are on the autism spectrum or have a learning disability, require extra support from a peer or adult. Children with speech limitations may not be able to participate in the same games, songs, or lessons as their peers. Alongside the behavioral characteristics of each child with a chronic health condition, congregational barriers may also explain why children with deficiencies in communication and social interaction are much more likely to never attend religious services.

These analyses also demonstrate the necessity of considering various childhood heath conditions separately as well as including a broad spectrum of conditions. The few previous studies that examined religious service attendance among children with chronic health conditions tend to focus on just one or two chronic health conditions. There are virtually no studies that consider children's religiosity alongside conditions related to anxiety, learning disabilities, or speech problems. Moreover, while a majority of the current literature on chronic health conditions and religion focuses on older adults, it is vital that future research focus on children. 
This is especially important given that some chronic health conditions among children, like autism spectrum disorders, continue to grow in prevalence both in the United States and abroad (Blumberg et al. 2013; Parner, Schendel, and Thorsen 2008). Increasing rates of prevalence will have implications for places of worship as well as the families who are now faced with a diagnosis of an autism spectrum disorder or some other health condition.

It is also important that future research on particular chronic health conditions consider the possibility of multi-morbidity. Multi-morbidity of chronic health conditions limit functional ability, constrain social participation, and decrease quality of life (Boyd and Fortin 2010; Griffith et al. 2017; Marventano et al. 2014). However, much of this research focuses on the influence of multi-morbidity within older adult populations. While an in-depth examination of each chronic health condition and its co-morbidity with one or more other health conditions is beyond the purview of this analysis, researchers could comprehensively examine each chronic health condition and determine which specific ones are most likely to co-occur and if this influences the ability of children to participate in religious services.

While children with chronic health conditions that are primarily physical in nature face many difficulties in day-to-day life, the health conditions examined across the three waves of the NSCH reveal no consistent associations with never attending religious services once various controls are taken into account. Children with chronic asthma, diabetes, epilepsy, vision problems, or hearing problems appear to never attend religious services at rates similar to children with no health conditions. However, one particular chronic health condition that is primarily physical - bone/joint/muscle problems - was significantly associated with never attending. It could be that congregations are better at overcoming the barriers that might exclude children with health conditions that are more physical in nature. It could also be that children 
with chronic health conditions that are primarily physical do not exhibit behavioral characteristics that might hinder their participation at religious services. A final explanation might be that the collection of health conditions that are more physical in nature in the NSCH is limited and a broader assortment might uncover consistent associations between chronic health conditions that are primarily physical and religious service attendance.

Given the consistency with which children with chronic health conditions attend religious services at lower rates, it is important to continue to explore not only why this is so, but the consequences - both positive and negative - of these associations. There are a number of possibilities. First, continuing to examine religious organizations for how they respond to children with chronic health conditions and disabilities will uncover whether these lower rates of attendance are a "supply-side" issue. It could be there are many families and children who would like to attend religious services at least periodically throughout the year, but cannot find a congregation in their religious tradition near them that will provide the necessary supports. The similar findings since 2003 suggest that there have been no systemic changes made across congregations to eliminate the barriers faced by children with a health condition. It is also important to compare across religious traditions concerning congregational responses to children with chronic health conditions and their families. Future analyses could draw on one aspect of Carter's (2007) attitudinal barriers. Such studies could examine how religious traditions and congregations have different explanations about the causes and implications of children's chronic health conditions and the effects these have on children and their families. Are various theodicies of disability or suffering influential in whether children with chronic health conditions and their families attend? 
Second, given the higher likelihood of children with chronic health conditions never attending religious services, it is important to investigate how this influences the rest of the family. Prior research shows that greater involvement in religious activities and organizations can have a detrimental effect on the mental and emotional health of parents of children with disabilities while private religiosity appears to be more beneficial (Ekas et al. 2009; Tarakeshwar and Pargament 2001). Perhaps the families and parents of the children who never attend are actually better off in some ways. There is evidence, though, that children with various chronic health conditions and their families can benefit from religious service attendance (Abbotts et al. 2004; Ault 2010; Kleinert et al. 2007; Meltzer et al. 2011; Swinton 2001). The complex influence of religious activity for children with chronic health conditions and their families warrants further examination.

Ongoing investigations of religious socialization and the rise of the unaffiliated might benefit from considering the influence of childhood chronic health conditions. The variation in religious socialization across family types and the influence of family disruption is under increased scrutiny (Denton 2012; Denton and Culver 2015; Petts 2015; Sullivan 2008; Zhai et al. 2007). However, the disruptions of divorce and alternative family structures on children's religious socialization receive the bulk of the attention. It is important to broaden the scope of possible family disruptions. Chronic health conditions, especially within children, can be significant family disruptions. Disability in children may also moderate the "upward influence" children tend to have on parental and family religiosity. Given the congregational barriers children with health conditions and their families face, it might be that caring for a child with a chronic health condition significantly influences decisions to leave one's faith. Regrettably, the NSCH does not ask parents (or siblings) for their level of religious service attendance. This 
analysis establishes that children with various chronic health conditions are much more likely to never attend religious services. These findings are only suggestive, though, concerning whether the rest of the family is more likely to never attend as well. If future studies were able to gather data on parental, sibling, or familial religious service attendance alongside the children with health conditions, various mechanisms of religious socialization and disengagement with organized religion could be considered.

Future research should also begin to explore interactions across various sociodemographic statuses and disability. Race, family structure, parental education, income, and child's age, to name a few, could possibly moderate the association between a number of these chronic health conditions and never attending religious services.

Fifth, it is important to realize that while children with various chronic health conditions are much more likely to never attend compared to their peers without a health condition, it does not necessarily mean that these families or children are not religious in other ways. Gathering data on the other avenues through which these families and children may be practicing their religion would tell us much about lived religion and the ways in which religiosity can flourish outside the walls of a church or synagogue (Bender et al. 2012). As congregations continue to struggle to include children with chronic health conditions and their families into the life of the organization, are the religious needs of families with a child with a chronic health condition being met elsewhere or in other ways? How are these families creatively addressing the barriers they face within organized religion?

\section{Conclusion}

Various chronic health conditions are significantly associated with children's reported religious service attendance. Across several waves of a nationally representative survey of 
children, those with autism spectrum disorders, developmental delays, learning disabilities, depression, anxiety, speech problems, and conduct disorders are consistently more likely to never attend religious services. Religious organizations are yet another sector of social life within which these children and perhaps their families struggle to integrate. Continuing to identify where in society children with chronic health conditions face deficits in participation is vital. While congregations influence more Americans than any other form of voluntary association (Chaves 2011), it is apparent that children with chronic health conditions are not as actively engaged as their counterparts who report no chronic health conditions. The decision for some of these children to never attend may be made irrespective of their condition. For others, though, the congregational and behavioral barriers are significant enough to make them much more likely to never attend religious services. Social scientists, congregational leaders, and mental health professionals interested in investigating and serving this population must continue to explore not only who is least likely to attend but why. 


\section{REFERENCES}

Abbotts, Joanne E., Rory G.A. Williams, Helen N. Sweeting, and Patrick B. West. 2004. Is going to church good or bad for you? Denomination, attendance and mental health of children in West Scotland. Social Science \& Medicine 58(3):645-56.

Ault, Melinda J. 2010. Inclusion of religion and spirituality in the special education literature. Journal of Special Education 44(3):176-89.

Ault, Melinda J., Belva C. Collins, and Erik W. Carter. 2013a. Congregational participation and supports for children and adults with disabilities: Parent perceptions. Intellectual and Developmental Disabilities 51(1):48-61.

. 2013b. Factors associated with participation in faith communities for individuals with developmental disabilities and their families. Journal of Religion, Disability \& Health 17(2):184-211.

Baio, Jon. 2014. Prevalence of autism spectrum disorder among children aged 8 years - autism and developmental disabilities monitoring network, 11 sites, United States, 2010. MMWR SS-63(2):1-21.

Barusch, Amanda. S. 1999. Religion, adversity and age: Religious experiences of low-income elderly women. Journal of Sociology and Social Welfare 26(1):125-42.

Bayat, Mojdeh. 2007. Evidence of resilience in families of children with autism. Journal of Intellectual Disability Research 51(9):702-14.

Bender, Courtney, Wendy Cadge, Peggy Levitt, and David Smilde. 2012. Religion on the edge: De-centering and re-centering the sociology of religion. New York, NY: Oxford University Press.

Bennett, Tess, Deborah A. Deluca, and Robin W. Allen. 1995. Religion and children with disabilities. Journal of Religion and Health 34(4):301-12.

Bernell, Stephanie and Steven W. Howard. 2016. Use your words carefully: What is a chronic disease? Frontiers in Public Health 4(159):1-3.

Blumberg, Stephen J., Lorayn Olson, Martin R. Frankel, Larry Osborn, K.P. Srinath, and Pamela Giambo. 2005. Design and operation of the National Survey of Children's Health, 2003. National Center for Health Statistics.

Blumberg, Stephen J., Erin B. Foster, Alicia M. Frasier, Jennifer Satorius, Ben J. Skalland, Kari L. Nysse-Carris, Heather M. Morrison, Sadeq R. Chowdhury, and Kathleen S. O'Connor. 2012. Design and operation of the national survey of children's health. 2007 Vital and Health Statistics. Ser.1. Programs and Collection Procedures, 55(June), 1-49. 
Blumberg, Stephen J., Matthew D. Bramlett, Michael D. Kogan, Laura A. Schieve, Jessica R. Jones, and Michael C. Lu. 2013. Changes in prevalence of parent-reported autism spectrum disorder in school-aged US children: 2007 to 2011-2012. National Health Statistics Reports 65(20): 1-7.

Boyd, Cynthia M. and Martin Fortin. 2010. Future of multimorbidity research: How should understanding of multimorbidity inform health system design? Public Health Reviews 32(2): 451-74.

Boyle, Coleen, Sheree Boulet, Laura Schieve, Robin A. Cohen, Stephen J. Blumberg, Marshalyn Yeargin-Allsopp, Susanna Visser, and Michael D. Kogan. 2011. Trends in the prevalence of developmental disabilities in US children, 1997-2008. Pediatrics 127(6):1034-42.

Campbell, James. D., Dong Phil Yoon, and Brick Johnstone. 2010. Determining relationships between physical health and spiritual experiences, religious practices, and congregational support in a heterogeneous medical sample. Journal of Religion and Health 49(1):3-17.

Carter, Erik W. 2007. Including people with disabilities in faith communities. Baltimore, MD: Brookes Publishing.

Centers for Disease Control. 2015. 53 million adults in the US live with a disability. Available at https://www.cdc.gov/media/releases/2015/p0730-us-disability.html, accessed May 4, 2017.

Chaves, Mark. 2011. American religion: Contemporary trends. Princeton, NJ: Princeton University Press.

Coulthard, Patricia. and Michael Fitzgerald. 1999. In God we trust?: Organised religion and personal beliefs as resources and coping strategies, and their implications for health in parents with a child on the autistic spectrum. Mental Health, Religion \& Culture 2(1):1933.

Denton, Melinda L. 2012. Family structure, family disruption, and profiles of adolescent religiosity. Journal for the Scientific Study of Religion 51(1):42-64.

Denton, Melinda L. and Julian Culver. 2015. Family disruption and racial variation in adolescent and emerging adult religiosity. Sociology of Religion 76(2):222-39.

Ekas, Naomi V., Thomas L. Whitman, and Carolyn Shivers. 2009. Religion, spirituality, and socioemotional functioning in mothers of children with autism spectrum disorder. Journal of Autism and Developmental Disorders 39(5):706-19.

Ellison, Christopher G. and Jeffrey S. Levin. 1998. The religion-health connection: Evidence, theory, and future directions. Health Education \& Behavior 25(6):700-20. 
Erickson, W., Lee, C., von Schrader, S. 2017. Disability Statistics from the American Community Survey (ACS). Ithaca, NY: Cornell University Yang-Tan Institute (YTI). Retrieved from Cornell University Disability Statistics website: www.disabilitystatistics.org Retrieved from Cornell University Disability Statistics website: www.disabilitystatistics.org

Gillum, R. F. and Harold D. Trulear. 2008. Mobility limitation and frequency of attendance at religious services in American women and men. Journal of Religion, Disability \& Health. 11(4):51-60.

Griffith, Lauren E., Parminder Raina, Melanie Levasseur, Nazmul Sohel, Helene Payette, Holly Tuokko, Edwin van den Heuvel, Andrew Wister, Anne Gilsing, and Christopher Patterson. 2017. Functional disability and social participation restriction associated with chronic conditions in middle-aged and older adults. Journal of Epidemiological Community Health 71(4): 381-9.

Hayward, R. David and Neal Krause. 2013. Trajectories of disability in older adulthood and social support from a religious congregation: A growth curve analysis. Journal of Behavioral Medicine 36(4):354-60.

Hill, Terrence D., Jacqueline L. Angel, Christopher G. Ellison, and Ronald J. Angel. 2005. Religious attendance and mortality: An 8-year follow-up of older Mexican Americans. The Journals of Gerontology, Series B: Psychological Sciences and Social Sciences 60(2):S102-S109.

Hummer, R. A., Maureen R. Benjamins, Christopher G. Ellison, and Richard G. Rogers. 2010. Religious involvement and mortality risk among pre-retirement aged U.S. adults. In Religion, Families and Health: Population-Based Research in the United States, edited by Christopher G. Ellison and Robert A. Hummer, pp: 273-91. New Brunswick, NJ: Rutgers University Press.

Idler, Ellen L., \& Stanislav Kasl. 1997a. Religion among disabled and nondisabled persons. I: Cross-sectional patterns in health practices, social activities, and well-being. Journal of Gerontology: Social Sciences, 52B:S294-S305.

. 1997b. Religion among disabled and nondisabled persons. II: Attendance at religious services as a predictor of the course of disability. Journal of Gerontology: Social Sciences 52B:S306-S316.

Kessler Foundation and National Organization on Disability. 2010. The ADA, 20 years later. Washington, DC: Author. Available at http://www.nasuad.org/hcbs/article/ada-20-yearslater-2010-survey-americans-disabilities.

Kleinert, Harold L., Sally Miracle, and Kathy Sheppard-Jones. 2007. Including students with moderate and severe intellectual disabilities in school extracurricular and community recreation activities. Intellectual and Developmental Disabilities 45(1):46-55. 
Koenig, Harold G., Judith C. Hays, Linda K. George, Dan G. Blazer, David B. Larson, and Lawrence R. Landerman. 1997. Modeling the cross-sectional relationships between religion, physical health, social support, and depressive symptoms. American Journal of Geriatric Psychiatry 5(2):131-44.

Koenig, Harold G., Judith C. Hays, Doug Larson, Laura George, Harvey J. Cohen, Michael McCollough, Keith G. Meador, and Daniel G. Blazer. 1999. Does religious attendance prolong survival? A six-year follow-up study of 3,968 older adults. The Journals of Gerontology. Series A, Biological Sciences and Medical Sciences 54:M370-M376.

Koenig, Harold. G., Dana E. King, Verna Benner Carson. 2012. Handbook of religion and health. New York, NY: Oxford University Press.

Lee, Li-Ching, Rebecca A. Harrington, Brian B. Louie, and Craig J. Newschaffer. 2008. Children with autism: Quality of life and parental concerns. Journal of Autism and Developmental Disabilities 38(6):1147-60.

Levin, Jeffrey S. and Linda M. Chatters. 1998. Religion, health, and psychological well-being in older adults: Findings from three national surveys. Journal of Aging and Health 10:50431.

Marventano, Stefano, Alba Ayala, Nerea Gonzalez, Carmen Rodriguez-Blazquez, Susana Garcia-Guitierrez, Maria Joao Forjaz, and the Spanish Research Group of Quality of Life and Ageing. 2014. Multimorbidity and functional status in community-dwelling older adults. European Journal of Internal Medicine 25(7): 610-6.

Meltzer, Howard I., Nisha Dogra, Panos Vostanis, and Tamsin Ford. 2011. Religiosity and the mental health of adolescents in Great Britain. Mental Health, Religion \& Culture 14(7):703-13.

O'Hanlon, Elizabeth E. 2013. Religion and disability: The experiences of families of children with special needs. Journal of Religion, Disability \& Health 17(1):42-61.

Orsmond, Gael I., Marty W. Krauss, and Marcha M. Seltzer. 2004. Peer relationships and social and recreational activities among adolescents and adults with autism. Journal of Autism and Developmental Disorders 34(3):245-256.

Parner, Erik T., Diana E. Schendel, and Poul Thorsen. 2008. Autism prevalence trends over time in Denmark: Changes in prevalence and age at diagnosis. Archives of Pediatrics \& Adolescent Medicine 162(12):1150-6.

Petts, Richard J. 2015. Parental religiosity and youth religiosity: Variations by family structure. Sociology of Religion 76(1):95-120. 
Phelps, Kenneth W., Susan L. McCammon, Karl L. Wuensch, and Jeannie A. Golden. 2009. Enrichment, stress, and growth from parenting an individual with an autism spectrum disorder. Journal of Intellectual \& Developmental Disability 34(2):133-41.

Poston, Denise J. and Ann P. Turnbull. 2004. Role of spirituality of religion in family quality of life for families of children with disabilities. Education and Training in Developmental Disabilities 39(2):95-108.

Shu, Bih-Ching. 2009. Quality of life of family caregivers of children with autism: The mother's perspective. Autism 13(1):81-91.

Sullivan, Susan Crawford. 2008. Unaccompanied children in churches: Low-income urban single mothers, religion, and parenting. Review of Religious Research 50(2):157-75.

Swinton, John. 2001. Building a church for strangers. Journal of Religion, Disability and Health 4(4):25-63.

Tarakeshwar, Nalini, and Kenneth I. Pargament. 2001. Religious coping in families of children with autism. Focus on Autism and Other Developmental Disabilities 16(4):247-61.

U.S. Department of Health and Human Services, Health Resources and Services Administration, Maternal and Child Health Bureau. 2005. The National Survey of Children's Health 2003. Rockville, Maryland: U.S. Department of Health and Human Services. . 2009. The National Survey of Children's Health 2007. Rockville, Maryland: U.S. Department of Health and Human Services.

. 2012. The National Survey of Children's Health 2011-2012. Rockville, Maryland: U.S. Department of Health and Human Services.

Visser, Susanna N., Melissa L. Danielson, Rebecca H. Bitsko, Joseph R. Holbrook, Michael D. Kogan, Reem M. Ghandour, Ruth Perou, and Stephen J. Blumberg. 2014. Trends in the parent-report of health care provider diagnosed and medicated ADHD: United States, 2003-2011. Journal of the American Academy of Child and Adolescent Psychiatry 53(1):34-46.

Vogel, Jeannine, Edward A. Polloway, and J. David Smith. 2006. Inclusion of people with mental retardation and other developmental disabilities in communities of faith. Mental Retardation 44(2):100-111.

Wagner, Mary, Tom W. Cadwallader, Camille Marder, Renee Cameto, Denise Cardoso, Nicolle Garza, Phyllis Levine, and Lynn Newman. 2003. Life outside the classroom for youth with disabilities. A report from the National Longitudinal Transition Study-2 (NLTS2). Menlo Park, CA: SRI International. 
White, Stacy E. 2009. The Influence of Religiosity on Well-Being and Acceptance in Parents of Children with Autism Spectrum Disorder. Journal of Religion, Disability \& Health 13(2):104-13.

Whitehead, Andrew L. 2016. Neighborhoods, family functioning, and mothers' mental health for families with a child with an autism spectrum disorder. Applied Research in Quality of Life 12(3):633-51.

Woolever, Cynthia and Deborah Bruce. 2002. A field guide to U.S. congregations: Who's going where and why. Louisville, KY: Westminster John Knox Press.

Yatchmenoff, Diane K., Paul E. Koren, Barbara J. Friesen, Lynwood J. Gordon, and Ronald F. Kinney. 1998. Enrichment and stress in families caring for a child with a serious emotional disorder. Journal of Child and Family Studies 7(2):129-145.

Zhai, Jiexia E., Christopher G. Ellison, Norval D. Glenn, and Elizabeth Marquardt. 2007. Parental divorce and religious involvement among young adults. Sociology of Religion 68(2):125-144. 
Table 1: Descriptive Statistics for National Survey of Children's Health, 2003-2012

\begin{tabular}{|c|c|c|c|c|}
\hline & Description & 2003 & 2007 & 2011-2012 \\
\hline Never Attend & $\begin{array}{l}1=\text { Never Attend } \\
\text { Religious Services }\end{array}$ & 21.41 & 20.68 & 23.53 \\
\hline Age & In years, 0-17 & 8.61 & 8.57 & 8.59 \\
\hline \multirow[t]{5}{*}{ Child's Health } & $5=$ Excellent & 60.87 & 61.28 & 60.51 \\
\hline & $4=$ Very Good & 23.21 & 23.08 & 23.65 \\
\hline & $3=$ Good & 12.70 & 12.16 & 12.69 \\
\hline & 2 = Fair & 2.85 & 3.03 & 2.73 \\
\hline & $1=$ Poor & .37 & .45 & .43 \\
\hline White† & $1=$ White, non-Hispanic & 60.74 & 56.20 & 52.91 \\
\hline Hispanic & $1=$ Hispanic & 17.57 & 20.48 & 23.48 \\
\hline Black & 1 = Black, non-Hispanic & 14.39 & 14.22 & 13.64 \\
\hline $\begin{array}{l}\text { Multiple race/Other } \\
\text { race }\end{array}$ & $\begin{array}{l}1=\text { Multiple race or } \\
\text { Other race }\end{array}$ & 7.29 & 9.10 & 10.34 \\
\hline Female & $1=$ Child is Female & 48.88 & 48.87 & 48.85 \\
\hline $\begin{array}{l}\text { Total children in } \\
\text { home }\end{array}$ & $\begin{array}{l}1=1 \text { Child to } 4=4 \text { or } \\
\text { more Children }\end{array}$ & 2.32 & 2.26 & 2.27 \\
\hline $\begin{array}{l}\text { Biological/Adoptive } \\
\text { Parents } \dagger\end{array}$ & $\begin{array}{l}1=\text { Two Biological } / \\
\text { Adoptive Parents }\end{array}$ & 61.87 & 67.79 & 64.63 \\
\hline Step-Parents & $\begin{array}{l}1=\text { Two Parent } \\
\text { Stepfamily }\end{array}$ & 8.34 & 7.60 & 8.64 \\
\hline Single Mother & $\begin{array}{l}1=\text { Single Mother, no } \\
\text { Father Present }\end{array}$ & 22.83 & 18.71 & 18.68 \\
\hline Other Type & $1=$ Other family type & 4.34 & 5.90 & 6.60 \\
\hline \multirow[t]{4}{*}{ Parents' Income } & $4=400 \%$ or more FPL & 26.68 & 29.34 & 27.82 \\
\hline & $3=200-399 \%$ FPL & 32.63 & 31.10 & 28.19 \\
\hline & $2=100-199 \%$ FPL & 22.84 & 20.99 & 21.54 \\
\hline & $1=<100 \%$ FPL to & 17.85 & 18.57 & 22.45 \\
\hline \multirow[t]{3}{*}{ Parents' Education } & $3=$ More than HS & 65.70 & 52.46 & 53.58 \\
\hline & 2 = HS Grad & 26.45 & 30.68 & 27.61 \\
\hline & $1=$ Less than HS & 7.86 & 16.86 & 18.80 \\
\hline Urban & $1=$ Urban & 77.37 & 81.29 & 79.71 \\
\hline Northeast & $1=$ Northeast & 17.77 & 17.16 & 16.76 \\
\hline Midwest & $1=$ Midwest & 22.39 & 21.90 & 21.57 \\
\hline South† & $1=$ South & 35.94 & 36.76 & 37.44 \\
\hline West & $1=\mathrm{West}$ & 23.90 & 24.18 & 24.26 \\
\hline Survey year & Total N & 102,353 & 91,642 & 95,677 \\
\hline
\end{tabular}

Note: Weighted data

$\dagger$ Contrast category 
Table 2: Prevalence of Chronic Health Conditions among US Children and Percent of Children with Each Chronic Health Condition Who Report Never Attending Religious Services, 2003-2012 (Percentages)

\begin{tabular}{|c|c|c|c|c|c|c|c|}
\hline \multirow[t]{2}{*}{ Condition } & \multirow[t]{2}{*}{ Description } & \multicolumn{3}{|c|}{$\begin{array}{l}\text { Prevalence Rates } \\
\text { (Percent) }\end{array}$} & \multicolumn{3}{|c|}{$\begin{array}{c}\text { Percent of Children Who Never Attend } \\
\text { Religious Services }\end{array}$} \\
\hline & & 2003 & 2007 & $2011-2012$ & 2003 & 2007 & 2011-2012 \\
\hline Children w/ No Condition & Child (0-17) has no condition & 73.39 & 77.54 & $76.66^{\mathrm{ab}}$ & 22.46 & 20.87 & $24.36^{\mathrm{ab}}$ \\
\hline Autism Spectrum Disorder & $\begin{array}{l}\text { Child (2-17) currently has } \\
\text { ASD }\end{array}$ & .54 & 1.12 & $1.90^{\mathrm{ab}}$ & $35.79^{c}$ & $32.72^{\mathrm{c}}$ & $32.10^{\mathrm{c}}$ \\
\hline Attention Deficit & Child (2-17) currently has & & & & & & \\
\hline $\begin{array}{l}\text { Disorder/Attention Deficit } \\
\text { Hyperactivity Disorder }\end{array}$ & ADD or ADHD & 7.27 & 6.73 & $7.92^{\mathrm{ab}}$ & $24.43^{\mathrm{c}}$ & $19.97^{\mathrm{c}}$ & $23.56^{\mathrm{c}}$ \\
\hline Developmental Delay & $\begin{array}{l}\text { Child (2-17) currently has a } \\
\text { Developmental Delay }\end{array}$ & 3.77 & 2.99 & $3.64^{\mathrm{a}}$ & $26.01^{\mathrm{c}}$ & $27.01^{\mathrm{c}}$ & $29.25^{\mathrm{bc}}$ \\
\hline Learning Disability & $\begin{array}{l}\text { Child (3-17) currently has a } \\
\text { Learning Disability }\end{array}$ & 9.71 & 7.50 & $7.84^{\mathrm{ab}}$ & $25.69^{c}$ & $22.72^{\mathrm{c}}$ & $27.09^{\mathrm{ac}}$ \\
\hline $\begin{array}{l}\text { Oppositional Defiant } \\
\text { Disorder/Conduct Disorder }\end{array}$ & $\begin{array}{l}\text { Child (2-17) currently has } \\
\text { ODD }\end{array}$ & 4.88 & 2.91 & $2.84^{b}$ & $29.51^{\mathrm{c}}$ & $25.86^{\mathrm{c}}$ & $29.19^{\mathrm{ac}}$ \\
\hline Asthma & $\begin{array}{l}\text { Child (0-17) currently has } \\
\text { Asthma }\end{array}$ & 11.95 & 8.67 & $8.62^{b}$ & 21.60 & 18.84 & $20.89^{a}$ \\
\hline Diabetes & $\begin{array}{l}\text { Child (0-17) currently has } \\
\text { Diabetes }\end{array}$ & .34 & .39 & .39 & 21.71 & $19.60^{\mathrm{d}}$ & 23.18 \\
\hline Bone/Joint/Muscle Problems & $\begin{array}{l}\text { Child (0-17) currently has } \\
\text { bone, joint, or muscle } \\
\text { problems }\end{array}$ & 3.47 & 2.30 & $2.36^{b}$ & 22.98 & 20.98 & $23.65^{\mathrm{ad}}$ \\
\hline Depression & $\begin{array}{l}\text { Child (2-17) currently has } \\
\text { Depression }\end{array}$ & --- & 2.06 & 2.08 & --- & $27.40^{c}$ & $29.92^{\mathrm{c}}$ \\
\hline Anxiety & $\begin{array}{l}\text { Child (2-17) currently has } \\
\text { Anxiety }\end{array}$ & --- & 3.26 & $3.84^{\mathrm{a}}$ & --- & $25.26^{\mathrm{c}}$ & $27.71^{\mathrm{ac}}$ \\
\hline Speech Problems & $\begin{array}{l}\text { Child (2-17) currently has } \\
\text { stuttering, stammering, or } \\
\text { other speech problems }\end{array}$ & --- & 3.28 & $4.54^{\mathrm{a}}$ & --- & $25.04^{\mathrm{c}}$ & $29.75^{\mathrm{ac}}$ \\
\hline Tourette Syndrome & $\begin{array}{l}\text { Child (2-17) currently has } \\
\text { Tourette Syndrome }\end{array}$ & --- & .18 & .19 & --- & 22.60 & 22.93 \\
\hline Brain Injury & $\begin{array}{l}\text { Child (0-17) currently has a } \\
\text { brain injury or concussion }\end{array}$ & --- & .28 & $.34^{\mathrm{a}}$ & --- & 26.21 & $30.98^{c}$ \\
\hline Epilepsy & $\begin{array}{l}\text { Child (0-17) currently has } \\
\text { Epilepsy }\end{array}$ & --- & .57 & .64 & --- & 23.90 & 27.14 \\
\hline Hearing Problems & $\begin{array}{l}\text { Child (0-17) currently has } \\
\text { Hearing Problems }\end{array}$ & --- & 1.34 & 1.28 & --- & 21.15 & $25.98^{\mathrm{ac}}$ \\
\hline
\end{tabular}


CHILDHOOD DISABILITY AND RELIGION

Vision Problems Child (0-17) currently has

vision problems that cannot be

corrected with glasses/contact

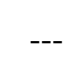

lenses

Intellectual Disability

Cerebral Palsy

Hearing or Vision Problems

Child (2-17) currently has an

Intellectual Disability

Child (0-17) currently has

Cerebral Palsy

Child (0-17) currently has

Hearing or Vision Problems

that cannot be corrected with

glasses/contact lenses

Depression or Anxiety

Child (2-17) currently has

Depression or Anxiety

Sources: 2003, 2007, 2011-2012 NSCH (Weighted data)

${ }^{a}$ Significant difference compared to $2007(\mathrm{p}<.05)$.

${ }^{b}$ Significant difference compared to $2003(\mathrm{p}<.05)$.

cPercent is significantly higher than children with no reported chronic health conditions in that survey year $(\mathrm{p}<.05)$.

dPercent is significantly lower than children with no reported chronic health conditions in that survey year $(p<.05)$. 
Table 3: Logistic Regression Models of Children's Chronic Health Conditions and Never Attending Religious Services (2011-2012, 2007, and 2003 NSCH - Weighted)

\begin{tabular}{|c|c|c|c|c|c|}
\hline & \multicolumn{2}{|c|}{ Condition Present } & \multicolumn{2}{|c|}{$\begin{array}{l}\text { Condition Absent - } \\
\text { Other Condition(s) } \\
\text { Present }\end{array}$} & \multirow[b]{2}{*}{$\mathrm{N}$} \\
\hline & $\mathrm{b}$ & OR & & & \\
\hline No condition & $-.127 * * *$ & .881 & --- & --- & $273,528^{\mathrm{a}}$ \\
\hline Autism Spectrum Disorder & $.610^{* * *}$ & 1.841 & $.131 * * *$ & 1.139 & $243,346^{\mathrm{a}}$ \\
\hline ADD/ADHD & $.177 * * *$ & 1.193 & $.140 * * *$ & 1.150 & $242,808^{\mathrm{a}}$ \\
\hline Developmental Delay & $.310 * * *$ & 1.363 & $.130^{* * * *}$ & 1.139 & $243,283^{\mathrm{a}}$ \\
\hline Learning Disability & $.311^{* * *}$ & 1.364 & $.099 * *$ & 1.104 & $230,834^{\mathrm{a}}$ \\
\hline $\begin{array}{l}\text { Oppositional Defiant } \\
\text { Disorder/Conduct Disorder }\end{array}$ & $.436^{* * *}$ & 1.546 & $.106^{* * *}$ & 1.112 & $243,433^{\mathrm{a}}$ \\
\hline Asthma & .022 & --- & $.194 * * *$ & 1.214 & $272,924^{a}$ \\
\hline Diabetes & -.012 & --- & $.129 * * *$ & 1.137 & $273,383^{\mathrm{a}}$ \\
\hline Bone/Joint/Muscle Problems & $.142 *$ & 1.153 & $.125^{* * *}$ & 1.133 & $273,253^{\mathrm{a}}$ \\
\hline Depression & $.546 * * *$ & 1.727 & $.129 * * *$ & 1.137 & $162,319^{b}$ \\
\hline Anxiety & $.370 * * *$ & 1.447 & $.136 * * *$ & 1.145 & $162,305^{\mathrm{b}}$ \\
\hline Speech Problems & $.351 * * *$ & 1.421 & $.116^{* *}$ & 1.124 & $162,405^{b}$ \\
\hline Tourette Syndrome & .055 & --- & $.162 * * *$ & 1.176 & $162,447^{\mathrm{b}}$ \\
\hline Brain Injury & $.534^{*}$ & 1.705 & $.128 * * *$ & 1.137 & $181,527^{b}$ \\
\hline Epilepsy & .141 & --- & $.134 * * *$ & 1.143 & $181,547^{\mathrm{b}}$ \\
\hline Hearing Problems & .132 & --- & $.131 * * *$ & 1.140 & $181,439^{\mathrm{b}}$ \\
\hline Vision Problems & .180 & --- & $.132 * * *$ & 1.141 & $181,398^{\mathrm{b}}$ \\
\hline Intellectual Disability & .360 & --- & $.141^{* *}$ & 1.151 & $82,640^{c}$ \\
\hline Cerebral Palsy & .215 & --- & $.147 * *$ & 1.158 & $82,681^{\mathrm{c}}$ \\
\hline Hearing or Vision Problems & -.126 & --- & $.124 * * *$ & 1.132 & $91,784^{\mathrm{d}}$ \\
\hline Depression or Anxiety & $.419 * * *$ & 1.521 & $.077^{*}$ & 1.080 & $81,015^{\mathrm{d}}$ \\
\hline
\end{tabular}

a $2011-2012,2007$

b2011-2012, $2007 \mathrm{NSCH}$

c2011-2012 NSCH

d2003 NSCH

Note: Every row represents a separate binary logistic regression model. No Condition(s) Present is the contrast category to which each column, Condition Present and Condition Absent - Other Condition(s) Present, is compared. The first row ("No condition"), however, compares all children with no reported chronic health conditions to all children who report a chronic health condition. Each model controls for child's age, child's health, white (contrast), Hispanic, black, multiple/other race, female, biological/adoptive parents (contrast), step-parents, single mother, other type, parents' income, parents' education, urban, Northeast, Midwest, South (contrast), West, and survey year (where applicable). 
Supplementary Table 1: Logistic Regression Models of 18 Children's Chronic Health Conditions and Never Attending Religious Services (2011-2012 NSCH - Weighted)

\begin{tabular}{lccccc}
\hline & \multicolumn{3}{c}{ Condition Present } & \multicolumn{3}{c}{$\begin{array}{c}\text { Condition Absent }- \\
\text { Other Condition(s) } \\
\text { Present }\end{array}$} \\
\hline & \multicolumn{1}{c}{$\mathrm{b}$} & $\mathrm{OR}$ & \multicolumn{3}{c}{$\mathrm{N}$} \\
\hline No condition & $-.125^{* *}$ & 0.883 & --- & --- & 92,408 \\
Autism Spectrum Disorder & $.567 * * *$ & 1.763 & $.116^{*}$ & 1.123 & 82,574 \\
ADD/ADHD & .057 & --- & $.173^{* * *}$ & 1.189 & 82,426 \\
Developmental Delay & $.323^{* *}$ & 1.381 & $.119^{*}$ & 1.126 & 82,583 \\
Learning Disability & $.316^{* * *}$ & 1.371 & .069 & --- & 78,533 \\
Depression & $.523^{* * *}$ & 1.687 & $.112^{*}$ & 1.119 & 82,604 \\
Anxiety & $.379^{* * *}$ & 1.461 & $.114^{*}$ & 1.121 & 82,593 \\
Oppositional Defiant & $.391^{* * *}$ & 1.479 & $.115^{*}$ & 1.122 & 82,620 \\
Disorder/Conduct Disorder & .360 & --- & $.141^{* *}$ & 1.151 & 82,640 \\
Intellectual Disability & .215 & --- & $.147^{* *}$ & 1.158 & 82,681 \\
Cerebral Palsy & $.468^{* * *}$ & 1.597 & .062 & --- & 82,633 \\
Speech Problems & -.153 & --- & $.145^{* *}$ & 1.157 & 82,654 \\
Tourette Syndrome & .049 & --- & $.167^{* *}$ & 1.181 & 92,216 \\
Asthma & .308 & --- & $.123^{* *}$ & 1.131 & 92,374 \\
Diabetes & .074 & --- & $.126^{* *}$ & 1.134 & 92,365 \\
Epilepsy & $.377^{* *}$ & 1.458 & $.108^{*}$ & 1.114 & 92,322 \\
Hearing Problems & .277 & --- & $.117^{* *}$ & 1.124 & 92,293 \\
Vision Problems & -.024 & --- & $.137^{* *}$ & 1.146 & 92,314 \\
Bone/Joint/Muscle Problems & $.723^{* *}$ & 2.060 & $.116^{* *}$ & 1.123 & 92,359 \\
Brain Injury & & & & &
\end{tabular}

$* \mathrm{p}<0.05 ; * * \mathrm{p}<0.01 ; * * * \mathrm{p}<0.001$

Note: Every row represents a separate binary logistic regression model. No Condition(s) Present is the contrast category to which each column, Condition Present and Condition Absent - Other Condition(s) Present, is compared. The first row ("No condition"), however, compares all children with no reported chronic health conditions to all children who report a chronic health condition. Each model controls for child's age, child's health, white (contrast), Hispanic, black, multiple/other race, female, total children in home, biological/adoptive parents (contrast), step-parents, single mother, other type, parents' income, parents' education, urban, Northeast, Midwest, South (contrast), West. 
Supplementary Table 2: Logistic Regression Models of 16 Children's Chronic Health Conditions and Never Attending Religious Services (2007 NSCH - Weighted)

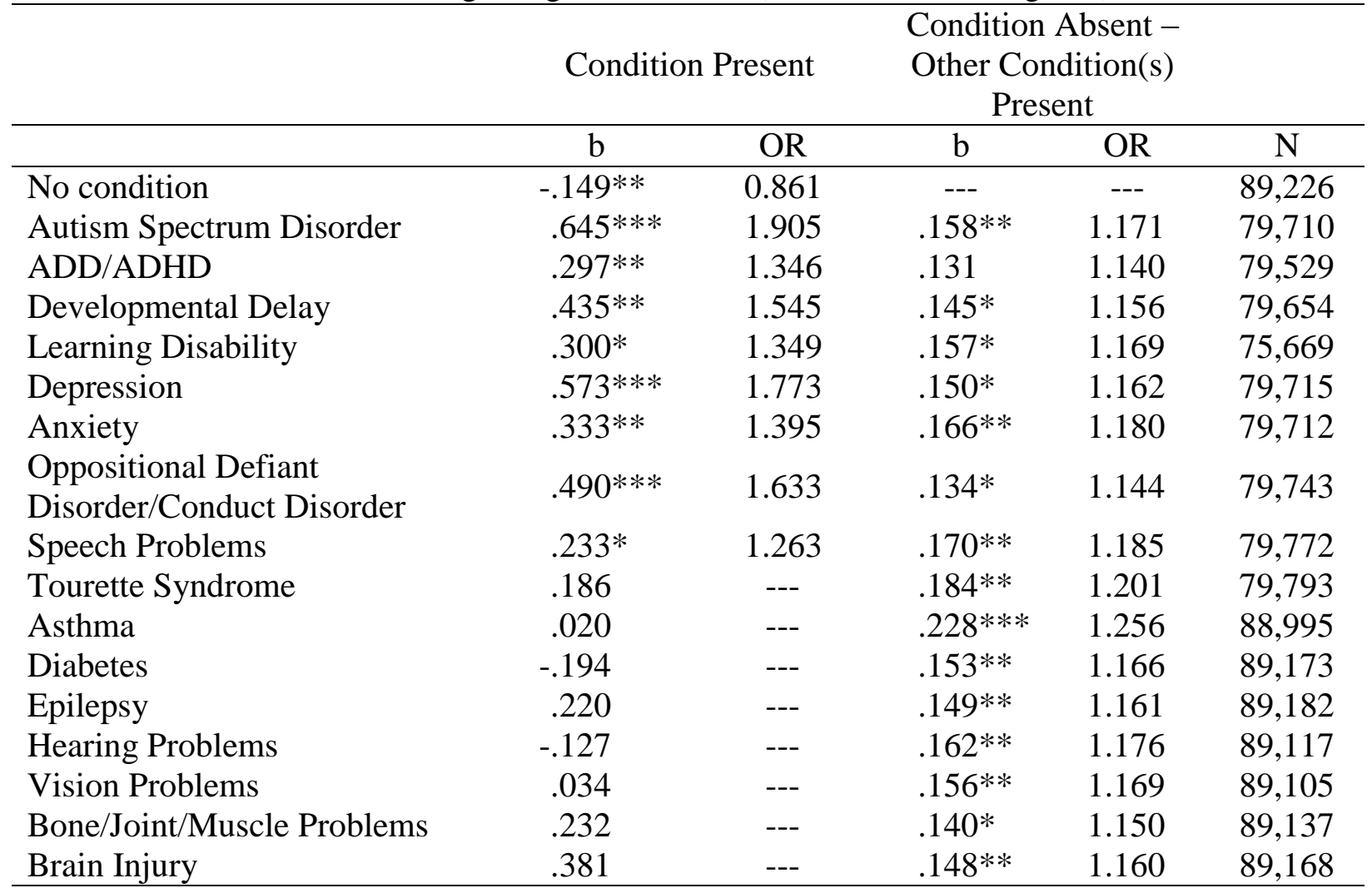

$* \mathrm{p}<0.05 ; * * \mathrm{p}<0.01 ; * * * \mathrm{p}<0.001$

Note: Every row represents a separate binary logistic regression model. No Condition(s) Present is the contrast category to which each column, Condition Present and Condition Absent - Other Condition(s) Present, is compared. The first row ("No condition"), however, compares all children with no reported chronic health conditions to all children who report a chronic health condition. Each model controls for child's age, child's health, white (contrast), Hispanic, black, multiple/other race, female, total children in home, biological/adoptive parents (contrast), step-parents, single mother, other type, parents' income, parents' education, urban, Northeast, Midwest, South (contrast), West. 
Supplementary Table 3: Logistic Regression Models of 10 Children's Chronic Health Conditions and Never Attending Religious Services (2003 NSCH - Weighted)

\begin{tabular}{|c|c|c|c|c|c|}
\hline & \multicolumn{2}{|c|}{ Condition Present } & \multicolumn{2}{|c|}{$\begin{array}{c}\text { Condition Absent - } \\
\text { Other Condition(s) } \\
\text { Present } \\
\end{array}$} & \multirow[b]{2}{*}{$\mathrm{N}$} \\
\hline & $\mathrm{b}$ & OR & $\mathrm{b}$ & OR & \\
\hline No condition & $-.102 * *$ & 0.903 & --- & --- & 91,894 \\
\hline Autism Spectrum Disorder & $.784 * * *$ & 2.191 & $.109 * *$ & 1.116 & 81,062 \\
\hline ADD/ADHD & $.222 * * *$ & 1.248 & $.100^{*}$ & 1.105 & 80,853 \\
\hline Developmental Delay & $.164 *$ & 1.178 & $.118^{* *}$ & 1.125 & 81,046 \\
\hline Learning Disability & $.273^{* * * *}$ & 1.314 & .079 & --- & 76,632 \\
\hline Depression or Anxiety & $.419 * * *$ & 1.521 & $.077^{*}$ & 1.080 & 81,015 \\
\hline $\begin{array}{l}\text { Oppositional Defiant } \\
\text { Disorder/Conduct Disorder }\end{array}$ & $.424 * * *$ & 1.528 & .058 & --- & 81,070 \\
\hline Asthma & -.015 & --- & $.198 * * *$ & 1.219 & 91,713 \\
\hline Diabetes & -.158 & --- & $.106^{* *}$ & 1.111 & 91,836 \\
\hline Hearing or Vision Problems & -.126 & --- & $.124 * * *$ & 1.132 & 91,784 \\
\hline Bone/Joint/Muscle Problems & $.167 *$ & 1.182 & $.097 * *$ & 1.102 & 91,802 \\
\hline
\end{tabular}

*p $<0.05 ; * * \mathrm{p}<0.01 ; * * * \mathrm{p}<0.001$

Note: Every row represents a separate binary logistic regression model. No Condition(s) Present is the contrast category to which each column, Condition Present and Condition Absent - Other Condition(s) Present, is compared. The first row ("No condition"), however, compares all children with no reported chronic health conditions to all children who report a chronic health condition. Each model controls for child's age, child's health, white (contrast), Hispanic, black, multiple/other race, female, total children in home, biological/adoptive parents (contrast), step-parents, single mother, other type, parents' income, parents' education, urban, Northeast, Midwest, South (contrast), West. 